\title{
Organic and inorganic selenium compounds produce different protein patterns in the blood plasma of rats
}

\author{
ANDREA V MAHN ${ }^{1}{ }^{*}$, HÉCTOR M TOLEDO $^{2}$ and MANUEL H RUZ 3 \\ ${ }^{1}$ Departamento de Ingeniería Química, Universidad de Santiago de Chile. \\ 2 Programa de Biología Celular y Molecular, Instituto de Ciencias Biomédicas, Facultad de Medicina, \\ Universidad de Chile. \\ ${ }^{3}$ Departamento de Nutrición, Facultad de Medicina, Universidad de Chile.
}

\begin{abstract}
Some selenium compounds offer important health benefits when administered at supranutritional doses, such as improvement of the immune system and of male fertility, and the prevention of some types of cancer. The traditional selenium indexes do not account for the metabolic status of this element among replete individuals. As a consequence, there is a need for new indexes that distinguish between repletion statuses of selenium. The aim of this work was to indentify some plasmatic proteins that respond to supranutritional doses of selenium, which could be proposed as new protein markers of selenium intake.

The effect on rats of dietary supplementation with either selenomethylselenocysteine (SMSeC) or sodiumselenate on some blood plasma proteins was investigated. Two experimental groups consisting of six rats each were fed a basic diet supplemented with either SMSeC or sodium-selenate at $1.9 \mu \mathrm{g}$-Se / g-diet for ten weeks. The control group was fed a diet that contained the recommended selenium dose $(0.15 \mu \mathrm{g}$-Se $/ \mathrm{g}$-diet $)$. The changes in the abundance of a group of plasmatic proteins were quantified and analysed statistically. Haptoglobin, apolipoprotein E and transthyretin increased their abundance after diet supplementation with either form of selenium. HNF6 was responsive only to SMSeC, whereas fibrinogen responded only to sodiumselenate. We postulate that the protein patterns observed in this work could be proposed as new molecular biology-based markers of selenium intake.
\end{abstract}

Key terms: selenium status, protein abundance, rat blood plasma, nutritional biomarkers

\section{INTRODUCTION}

Selenium $(\mathrm{Se})$ is an essential trace element that offers several health benefits to animals and humans. Low dietary selenium has deleterious effects on health and may result in cancer, cardiovascular disease, and immune dysfunction (Pagmantidis et al., 2008), among others. In the past decade, the main interest was focused on the anticarcinogenic properties of Se. There is evidence for the chemoprotective effect of selenium ( $\mathrm{Se}$ ) against some types of cancer (Clark et al., 1996; Clark et al., 1998; Finley et al., 2000; Zhuo et al., 2004; Unni et al., 2005; Li et al., 2006; Li et al., 2008; Gundimeda et al., 2008; and Bhattacharyya et al., 2008). The mechanism by which Se exerts its beneficial effects are not yet fully understood, however it is believed that selenoproteins and selenium compounds of low molecular weight have an important role (Irons et al., 2006).

Many of the beneficial effects of Se, such as cancer prevention, improvement of male fertility and enhancement of the immune system, take place when supranutritional doses of this element are administered (Fleming et al., 2001; Hurwitz et al., 2007; Safarinejad and Safarinejad, 2009). Additionally, those effects depend on the chemical form of $\mathrm{Se}$ that was administered. For example, it was shown that selenomethylselenocysteine (SMSeC) offers the highest chemoprotection against colon cancer, as compared either with selenomethionine or with inorganic salts, such as selenite and selenate (Finley et al.,

\footnotetext{
* Corresponding author: Andrea V. Mahn, Av. Libertador Bernardo O’Higgins 3363, Estación Central, Santiago, Chile, email: amahn_2000@yahoo.es-andrea.mahn@usach.cl, Phone: 56-2-7181833,Fax: 56-2-6817135
} 
2000; Finley and Davis, 2001; Ip et al., 2000). On the other hand, organic selenium compounds do not produce selenium accumulation in cells, and therefore the oxidative stress caused by selenium accumulation can be prevented (Shalini and Bansal, 2007).

Selenium bioavailability in mammals has been usually determined in blood plasma by means of biochemical indexes, such as the selenium concentration, the activity of glutathione peroxidase (Clark et al., 1996), and the relative abundance of selenoprotein $P$, the most abundant selenoprotein in blood plasma (Brown and Arthur, 2001; Johtatsu et al., 2007). Recently, Sunde et al. (2008) conducted a longitudinal repletion study to investigate the efficacy of molecular biology markers for assessing Se status in humans. They found that there were no significant longitudinal effects on the traditional Se biomarkers. In addition, the authors observed that the molecular and the biochemical markers reached a plateau in their response curves, and hence these Se indexes are unable to distinguish differences in the $\mathrm{Se}$ status of replete subjects. Additionally, Gromadzinska et al. (2008) reported that selenoproteins reach a plateau when supranutritional doses of Se are administered, and consequently they would not be suitable indexes of Se status in repletion studies.

The preceding antecedents led us to hypothesize that some plasmatic proteins, different from the traditional Se markers, would respond to Se supplementation in supranutritional doses, and could probably be proposed as alternative Se status biomarkers to be used in nutritional diagnosis.

This work investigated the effect of dietary supplementation with two selenium compounds (SMSeC and sodium-selenate) at supranutritional doses on the abundance of some proteins of the blood plasma of rats. The aim of this study was to determine whether the intake of either SMSeC or sodium-selenate above the recommended dose is reflected as differences in the abundance of some plasmatic proteins. Two-dimensional gel electrophoresis was used to determine changes in the abundance of the proteins, and mass spectrometry was used to identify those proteins.

\section{METHODS}

Experimental design and statistical analysis

The doses of Se used in this study were selected on the basis that some of the beneficial effects of Se take place when supranutritional doses of this element are fed (Fleming et al., 2001; Hurwitz et al., 2007; Safarinejad and Safarinejad, 2009). A dose of $0.15 \mu \mathrm{g} \mathrm{Se} / \mathrm{g}$ diet is slightly above the recommended dose $(0.14 \mu \mathrm{g} \mathrm{Se} / g$ diet $)$, and $2.0 \mu \mathrm{g} \mathrm{Se} / \mathrm{g}$ diet is near the toxicity limit (Suzuki, 2005). Thus, in order to prevent toxic effects on the experimental animals, $1.9 \mu \mathrm{g}$ Se /g diet was chosen as the dose to be used in the experimental groups. The feeding period was ten weeks, because some effects of supranutritional administration of Se have been observed within this period of time in similar studies in rats (Finley et al., 2000).

Plasma samples were collected, pooled in each experimental or control group, and analysed by 2D-gel electrophoresis. The normalized spot volume (relative abundance) of each of 21 proteins was determined densitometrically in quadruplicate from the gel images. Statistically significant differences (MannWhitney test at a $95 \%$ confidence interval) in the relative abundance of proteins were obtained by comparing the normalized volumes of the spots corresponding to each experimental group and the control group. Statistical analysis was carried out using Statgraphics ${ }^{\mathrm{TM}} 5.1$ software. Finally, protein identification was performed by mass spectrometry analysis.

\section{Animals}

Experimental groups of six Wistar rats, 21days old, were fed a Torula yeast-based diet (Dyets Inc, Bethlehem, USA) supplemented with $1.9 \mu \mathrm{g}$ Se $/ g$ diet of either SMSeC (group 1) or sodium selenate (group 2) during a feeding period of 10 weeks. A 
control group consisting of 6 rats was fed a basic diet supplemented with $0.15 \mu \mathrm{g} \mathrm{Se} / \mathrm{g}$ diet of sodium selenate, which delivers the recommended amount of selenium. Animals were maintained at $20^{\circ} \mathrm{C}, 12 \mathrm{~h} / 12 \mathrm{~h}$ day/ night cycles in stainless steel cages with free access to deionised water and the corresponding diet.

\section{Plasma samples}

After the experimental feeding period, blood from each rat was collected by cardiac puncture, using standard protocols (Ruz et al., 1999). Collection was made in heparin tubes (BD Biosciences, USA). The tubes were inverted up and down ten times and immersed in an ice bath. The tubes were centrifuged at $1300 \mathrm{RCF}$ for ten min at $4^{\circ} \mathrm{C}$. Plasma was separated from the solids. Supernatant was transferred to a new centrifuge tube and centrifuged at 2400 $\mathrm{RCF}$ for $15 \mathrm{~min}$ at $4^{\circ} \mathrm{C}$, in order to discard micro platelets. Plasma samples were kept at $-80^{\circ} \mathrm{C}$ until analysis.

\section{Total selenium concentration}

Total selenium concentration in the blood plasma of each animal was determined analytically after the dietary supplementation period. An atomic absorption spectrophotometer with a graphite furnace (Perkin Elmer Inc., USA) was used, following the protocol described by Jacobson and Lockitch (1988) and adapted for plasma samples. Selenium concentration was expressed as $\mu$ mol of elemental selenium per L of plasma. The results were analysed statistically by means of a Student's t test at $95 \%$ level.

\section{Sample preparation}

Plasma samples collected from the six rats of each experimental group were pooled, in order to normalize the variations among the animals, and depleted of albumin using the Qproteome $^{\mathrm{TM}}$ Murine Albumin Depletion Kit (QIAGEN GmbH, Germany), following the instructions of the manufacturer. Albumin depletion is frequently used in proteomics studies, and shows high reproducibility (Gupta et al., 2007). This procedure is used to reduce the wide range of protein concentration found in plasma, thus allowing the detection of lower abundance proteins. Protein concentration in plasma was determined according to the Bradford method using BSA as protein standard. The albumin-depleted protein solutions were freeze-dried and kept at $20^{\circ} \mathrm{C}$ until electrophoretic analysis.

\section{$2 D$ gel electrophoresis}

Proteins in the albumin-depleted plasma were fractionated by 2D gel electrophoresis using the method of Toledo et al. (2002) that is based on that described by O'Farrell (1975). Briefly, $300 \mu \mathrm{g}$ of protein from the albumin-depleted plasma were resuspended in $50 \mathrm{~mL}$ of lysis buffer $(9.5 \mathrm{M}$ urea, $2 \%$ Triton X-100, $1.6 \%$ ampholytes 4-7 range, $0.4 \%$ ampholytes 3-10 range, and $5 \% \beta$ mercaptoethanol), incubated at room temperature for $15 \mathrm{~min}$ and loaded onto labmade first dimension gels $(115 \mathrm{~mm}$ height and $3 \mathrm{~mm}$ internal diameter capillary tubes). A 4.0-7.0 pH gradient was used. Gel prefocusing was carried out according to the following program: $200 \mathrm{~V}$ for $15 \mathrm{~min}$, $300 \mathrm{~V}$ for $15 \mathrm{~min}$ and $400 \mathrm{~V}$ for $15 \mathrm{~min}$. Isoelectric focusing (IEF) was performed at $400 \mathrm{~V}$ for $20 \mathrm{~h}$, to complete $8000 \mathrm{Vh}$. After IEF, the gels were extruded and equilibrated immediately in $2 \mathrm{~mL}$ of equilibration solution $(10 \%$ glycerol, $5 \%$ bmercaptoethanol, $2.3 \%$ SDS, $0.0625 \mathrm{M}$ Tris-HCl pH 6.8) for $10 \mathrm{~min}$. Vertical SDSPAGE was run with lab-made homogeneous acrylamide gel (11.5\% acrylamide; 180 $\mathrm{mm}$ height and $120 \mathrm{~mm}$ wide), at a constant voltage of $50 \mathrm{~V}$ during $16 \mathrm{~h}$. Gels were soaked in a solution of $25 \%$ methanol and $7.5 \%$ acetic acid for $30 \mathrm{~min}$, stained in Coomassie Brilliant Blue R-250 for $12 \mathrm{~h}$ (0.1\% Coomassie blue R250, 25\% methanol, $7.5 \%$ acetic acid) and destained in a solution of $25 \%$ methanol and $7.5 \%$ acetic acid. Coomassie Blue staining is the most reliable quantitative protein staining method and is widely used in proteomics studies (Li et al., 2007). All chemicals were analytical grade and were purchased form Sigma Co. (St. Louis, MO, USA). 


\section{Image analysis}

Image acquisition was performed with an ImageScanner II device (GE Healthcare, Uppsala, Sweden). Intensity calibration was carried out using an intensity step wedge prior to the image capture. The Total Lab ${ }^{\mathrm{TM}}$ v2.01 software was used for image analysis. Spots were automatically detected and matched. Each spot volume was determined densitometrically and processed by background subtraction. Spot volumes of all gels were normalized by dividing the raw quantity of each spot by the total quantity of all valid spots in that gel, as recommended in literature (Grove et al., 2006; Kim et al., 2006).

\section{Protein identification by mass spectrometry analysis}

Protein spots were excised directly from the gels and analysed by MALDI-TOF at the University of Colorado Health Sciences Centre (UCHSC), USA. Gel bands were cut into small pieces to enhance cleaning of bands and trypsin absorption. Bands were manually digested using the standard Proteomics Core protocol (Rosenfeld et al., 1992; Hellman et al., 1995). Samples were digested overnight with modified porcine trypsin at room temperature. Digest solution was spotted on a MALDI target with alphacyano-4-hydroxycinnamic acid for sample co-crystallization. Samples were analysed using MALDI - TOF mass spectrometry in a Voyager DE-STR system (PerSeptive Biosystems Inc., MA, USA). Data was calibrated, deisotoped and centroided and a peak list was generated. Peak lists were searched using the MASCOT search engine (http: //www.matrixscience.com) against the nrNCBI database v20070204/Rodent subset.

\section{RESULTS}

Total concentration of selenium was determined in plasma samples in order to investigate the effect of different forms of selenium on this commonly used index of selenium status. The concentration of selenium in plasma was slightly higher in animals fed the selenium-supplemented diets, as compared to the control group (data not shown). However, there were no statistically significant differences between the control and the experimental groups at a $95 \%$ confidence ( $\mathrm{p}-\mathrm{value}=0.327)$. Additionally, no significant differences in the plasmatic selenium concentration were observed between the animals fed with SMSeC or with sodium-selenate, at a $95 \%$ confidence interval ( $\mathrm{p}$-value $=0.857$ ).

Representative gels of the control group and the group fed the SMSeC-supplemented diet are shown in Figure 1. The results of protein identification by mass spectrometry are presented in Table I, and refer to the spots shown in Figure 1. Densitometric analysis of the gels corresponding to each condition is shown in Figure 2. Relative abundance of individual proteins was compared between the animals fed with either SMSeC or with sodium-selenate, and also with the control group. Figure 2 shows that the protein spots numbers 1, 3, 11 and 21 were more abundant in plasma from rats fed diets supplemented with $\mathrm{SMSeC}$, as compared to the sodium-selenate group or the control group. The protein spots 8,9 and 12 in both experimental groups showed a lower abundance compared with the control group, whereas the protein spots $7,10,13$, 15,16 and 19 were more abundant in the sodium-selenate supplemented group, as compared to the SMSeC-supplemented group or the control group. Protein spots 1 , $2,3,4,6,8,9,12$ and 21 showed a lower abundance in the plasma of the sodiumselenate supplemented group, as compared to the control group. Finally, protein spots $13,15,16$ and 19 were more abundant in the plasma of rats fed diets supplemented with either form of selenium (SMSeC or sodiumselenate) in comparison to the control group. Statistical analyses of the above mentioned differences are shown in Table II.

\section{DISCUSSION}

The total concentration of selenium in blood plasma from any of the experimental groups (consisting of rats fed diets supplemented with either SMSeC or 
(a)

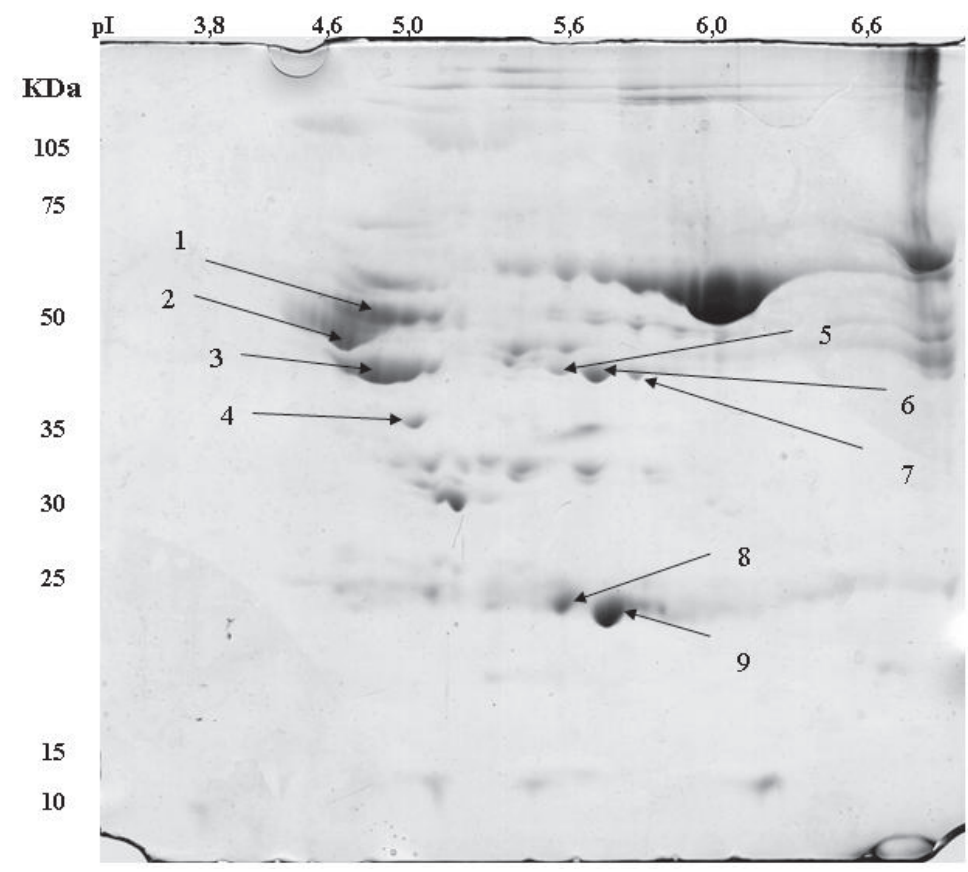

(b)

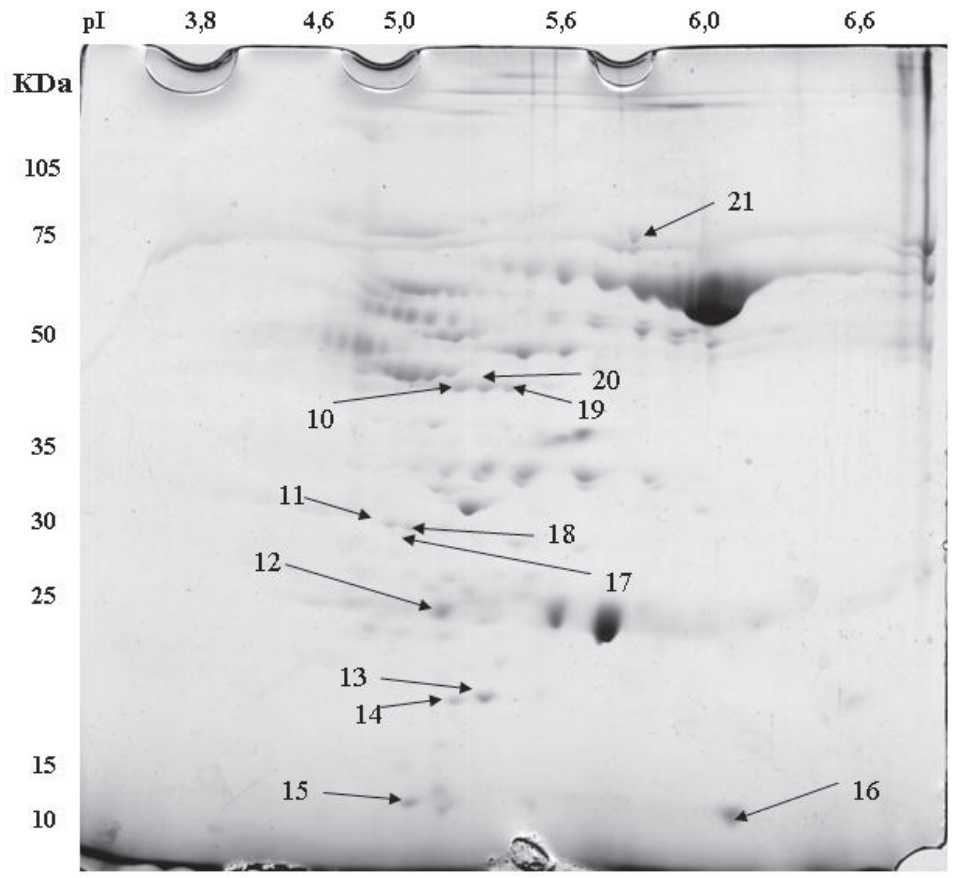

Figure 1: Representative gel images of (a) control group: $0.15 \mathrm{mg}$ Se (as sodium selenate) per $\mathrm{g}$ diet, and (b) experimental group: $1.9 \mathrm{mg} \mathrm{Se}$ (as SMSeC) per g diet. For each condition (experimental and control), 2D gels were made in quadruplicate and were stained with Coomassie Brilliant Blue R-250. Each gel was analysed densitometrically, and the relative abundance of each spot was calculated. Spot numbers indicating the proteins that were modulated by selenium are highlighted in the figure. The protein spots were analysed by mass spectrometry in order to determine their identity. 
sodium-selenate) shows no statistically significant differences compared to the control group. Nor were there significant differences in the indexes between the experimental group fed the diet supplemented with SMSeC compared to the one fed the diet supplemented with sodiumselenate. In our view, these observations suggest that the total concentration of selenium in blood plasma would not be a suitable index of selenium intake at supranutritional doses. These results agree with those published by Sunde et al. (2008) and Gromadzinska et al. (2008), who found that the biochemical and the molecular markers of Se status show saturation behaviour, and then they are not able to distinguish between different Se statuses above the recommended dose.

When an organic or an inorganic form of selenium supplemented the diet, differences in the plasmatic protein pattern, in comparison to the control group, were observed. In addition, the experimental groups fed with the two different forms of selenium displayed differences in the abundance of some plasmatic proteins. These different protein patterns would not be associated with any toxicity effect, because the experimental animals did not show any toxicity symptoms during the whole experimental period.

TABLE I

Mass spectrometry analysis. Spot Nr: number assigned to each spot in Figure 1. Score and Expect Value: parameters given by the Mascot search engine; a high score and a low Expected Value represent a low probability that the search result is a random result, i.e. low probability that the result is a false positive.

\begin{tabular}{lcccc}
\hline Spot Nr. & Protein & Sequence coverage (\%) & Score & Expected Value \\
\hline 1 & Hepatic nuclear factor 6 (HNF6) & 97 & 26 & $3.70 \mathrm{E}-02$ \\
2 & Contrapsin-like protease inhibitor (CPi-21) & 64 & 184 & $6.50 \mathrm{E}-14$ \\
3 & Alpha-1-antitrypsin & 66 & 191 & $1.30 \mathrm{E}-14$ \\
4 & Apolipoprotein A-IV & 83 & 338 & $2.00 \mathrm{E}-29$ \\
5 & Fibrinogen & 71 & 220 & $1.60 \mathrm{E}-17$ \\
6 & Fibrinogen & 62 & 174 & $6.50 \mathrm{E}-13$ \\
7 & Fibrinogen & 58 & 135 & $5.20 \mathrm{E}-09$ \\
8 & Apolipoprotein A-I & 78 & 155 & $5.20 \mathrm{E}-11$ \\
9 & Apolipoprotein A-I & 83 & 207 & $3.30 \mathrm{E}-16$ \\
10 & Alpha-1-antitrypsin precursor & 63 & 213 & $8.20 \mathrm{E}-17$ \\
11 & Cyclin H & 34 & 52 & $9.20 \mathrm{E}-01$ \\
12 & Immunoglobulin light chain & 64 & 101 & $1.30 \mathrm{E}-05$ \\
13 & Apolipoprotein E & 46 & 81 & $1.20 \mathrm{E}-03$ \\
14 & Apolipoprotein E & 71 & 119 & $2.10 \mathrm{E}-07$ \\
15 & Haptoglobin & 34 & 84 & $6.50 \mathrm{E}-4$ \\
16 & Rat Transthyretin & 89 & 106 & $4.10 \mathrm{E}-06$ \\
17 & Apolipoprotein A-IV & 33 & 133 & $8.20 \mathrm{E}-09$ \\
18 & Zinc finger protein 108 & 27 & 60 & $1.60 \mathrm{E}-01$ \\
19 & Alpha-1-antitrypsin & 66 & 290 & $1.60 \mathrm{E}-24$ \\
20 & Alpha-1-antitrypsin & 56 & 273 & $8.20 \mathrm{E}-23$ \\
21 & Gelsolin & 60 & 233 & $8.20 \mathrm{E}-19$ \\
\hline
\end{tabular}


(a)

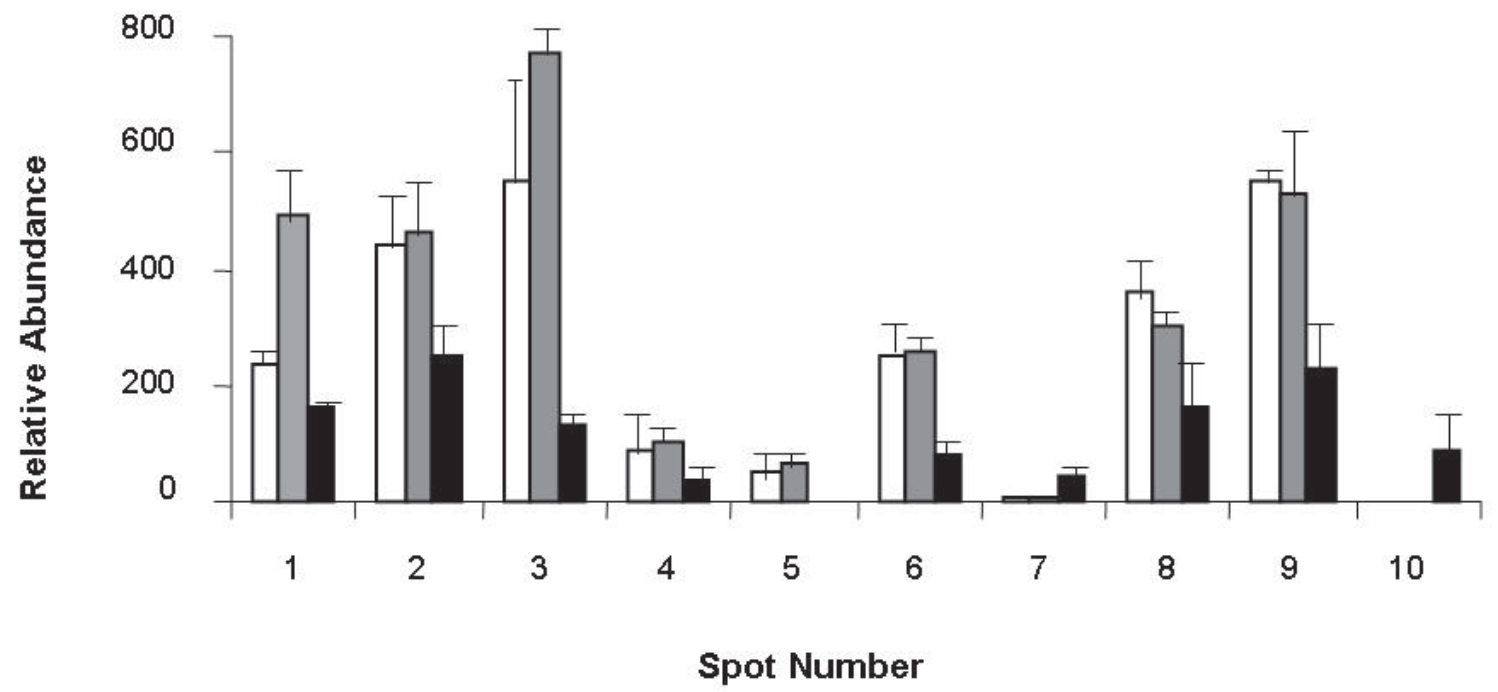

(b)

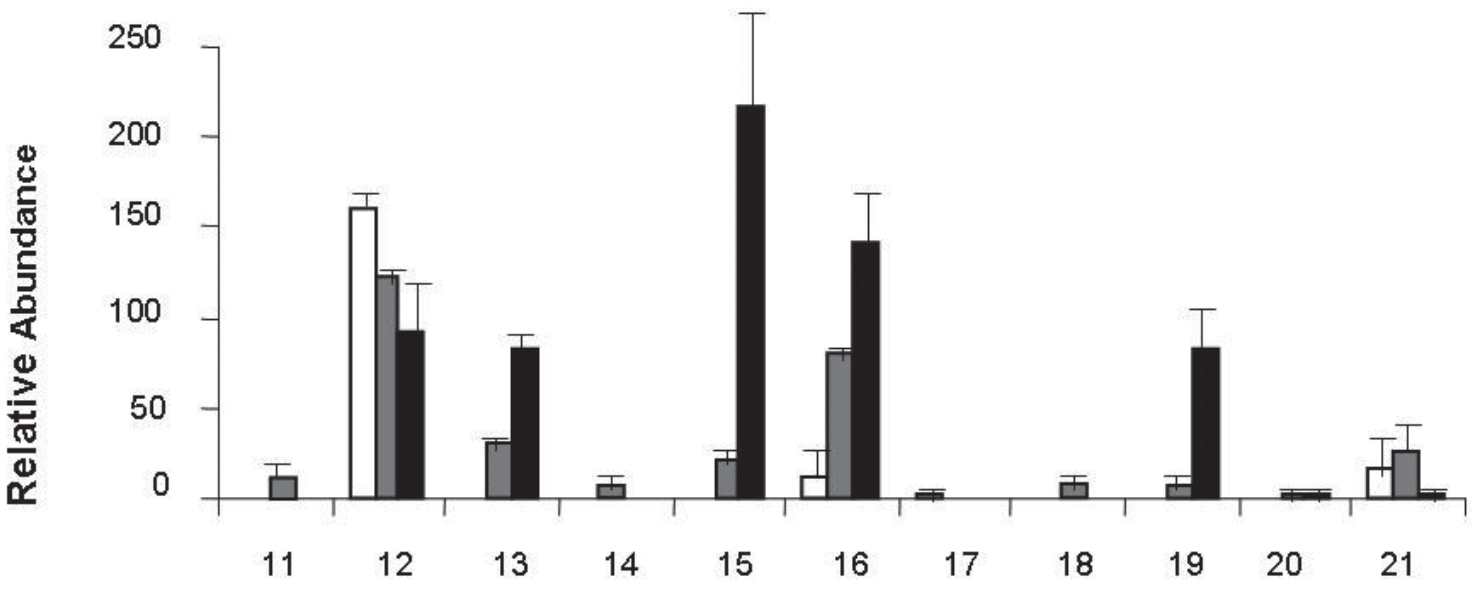

Spot Number

Figure 2: Effect of dietary supplementation with two forms of selenium on the relative abundance of plasmatic proteins in rats: Relative abundance (arbitrary units) of individual protein spots was calculated from four gel replicates. Values are the mean \pm standard deviation. Panel (a): spots 1 through 10; panel (b): spots 11 through 21. Control, SMSeC-supplemented diet and sodiumselenate-supplemented diet are represented as open, grey-filled and black-filled bars, respectively. 
On the other hand, a statistically significant increase in the abundance of some plasmatic proteins was observed in both groups of rats that were fed diets supplemented with either form of selenium, $\mathrm{SMSeC}$ or sodium-selenate, in comparison to the control group. Those proteins were apolipoprotein E (spot 13), haptoglobin (spot 15) and transthyretin (spot 16). However, no significant differences were observed in the abundance of those proteins between the $\mathrm{SMSeC}$ and the sodium-selenate groups (p- values $0.245,0.081$ and 0.51 , respectively). Accordingly, an increase in the relative abundance of those three proteins could be indicative of the intake of a supranutritional dose of selenium but it would not distinguish between the organic and the inorganic form of this element. Apolipoprotein $\mathrm{E}$ is a secreted protein that mediates the binding, internalization and catabolism of lipoprotein particles. It serves as ligand for the LDL receptor and for the specific apo-E receptor of hepatic tissues. Selenium deficiency has

TABLE II

Statistical analysis of the relative abundance of proteins: The p-values obtained from the comparison of protein abundances among the two experimental groups and the control group are shown. The average of the relative abundance of each protein spot was

calculated from four replicates of 2D-gel electrophoresis. A Mann-Whitney test was made considering a $95 \%$ confidence interval, in order to detect significant differences. n.d. indicates that the analysis could not be performed because the normalized volume either in the experimental or the control group was zero. (*) indicates statistically significant differences.

\begin{tabular}{lccc}
\hline Spot $\mathrm{Nr}$ & Inorganic/control & Organic/control & Inorganic/organic \\
\hline 1 & 0.052 & $0.030^{*}$ & $0.030^{*}$ \\
2 & 0.149 & 0.337 & 0.061 \\
3 & 0.245 & 0.245 & $0.030^{*}$ \\
4 & 0.052 & 0.596 & $0.030^{*}$ \\
5 & n.d. & 0.699 & n.d. \\
6 & 0.081 & 0.663 & $0.029^{*}$ \\
7 & $0.029^{*}$ & 0.306 & $0.029^{*}$ \\
8 & 0.245 & 0.105 & $0.049^{*}$ \\
9 & $0.050^{*}$ & 0.384 & 0.051 \\
10 & n.d. & n.d. & n.d. \\
11 & n.d. & n.d. & n.d. \\
12 & $0.030^{*}$ & $0.030^{*}$ & 0.051 \\
13 & n.d. & n.d. & 0.245 \\
14 & n.d. & n.d. & n.d. \\
15 & n.d. & n.d. & 0.081 \\
16 & $0.030^{*}$ & $0.030^{*}$ & 0.051 \\
17 & n.d. & n.d. & n.d. \\
18 & n.d. & n.d. & n.d. \\
19 & n.d. & n.d. & 0.051 \\
20 & n.d. & n.d. & 0.698 \\
21 & 0.698 & 0.698 & 0.245 \\
\hline
\end{tabular}


been associated with an increased level of apolipoprotein $\mathrm{E}$ in rat plasma, although the mechanism by which selenium deficiency affects lipoprotein metabolism is poorly understood (Mazur et al., 1996). Such effect has been attributed to housekeeping selenoproteins, which would have a role in the regulation of the biosynthesis and metabolism of lipoproteins (Sengupta et al., 2008). Transthyretin is a hormone-binding protein, rich in aromatic amino acids, that transports thyroxin from the blood stream to the brain. It is synthesized in the liver and in the choroid plexus (Navab et al., 1977). This protein is involved in the metabolism of the thyroid hormone and selenium seems to play a major regulatory function on thyroid hormone homeostasis (Kohrle, 1992). Such metabolic control is performed through the antioxidant activity of several selenoenzymes that are synthesized in the thyroid gland (Schmutzler et al., 2007). Both apolipoprotein $\mathrm{E}$ and transthyretin would be indirectly related to selenium metabolism. Haptoglobin binds free haemoglobin that is released from erythrocytes, and inhibits its oxidative activity. It also prevents iron loss through the kidneys and protects these organs from damage caused by haemoglobin (Yang et al., 1983). The relationship of haptoglobin with selenium metabolism remains to be clarified.

Hepatic nuclear factor 6 (HNF6, spot 1) underwent a significant increase in abundance when SMSeC supplemented the diet, as compared to the control group (pvalue $=0.030$ ). Additionally, significant differences were found in the abundance of this protein after diet supplementation with different forms of selenium ( $\mathrm{p}$-value $=$ $0.030)$. In contrast, no significant difference was observed in the abundance of this protein between the experimental group fed the diet supplemented with sodium-selenate and the control group ( $\mathrm{p}$-value $=0.052)$. Thus, an increase in the abundance of HNF6 in blood plasma could reflect the intake of SMSeC in a supranutritional dose, and probably it could distinguish between the organic and the inorganic forms of selenium.

Alpha-1-antitrypsin (spot 3) and apolipoprotein AIV (spot 4) showed a significant decrease in abundance after dietsupplementation with sodium-selenate as compared to the $\mathrm{SMSeC}$ group (p-values 0.030 and 0.030 , respectively). However, both proteins were equally abundant in the experimental group fed the SMSeCsupplemented diet and in the control group (p-values 0.245 and 0.596 , respectively).

Fibrinogen (spot 7) and alpha-1antitrypsin (spot 19) were significantly more abundant in rats fed the diet supplemented with sodium-selenate, in comparison to the control group (p-values 0.029 and n.d., respectively). Besides, fibrinogen was significantly more abundant in comparison to the group of rats that received the SMSeC-supplemented diet (pvalue 0.029). Thus, a significant increase in the abundance of that protein seems to reflect the intake of sodium selenate in a supranutritional dose.

In conclusion, haptoglobin, apolipoprotein $\mathrm{E}$ and transthyretin were found to significantly increase their abundance in the blood plasma of rats when a supranutritional dose of any form of selenium (SMSeC or sodium-selenate) supplemented the diet. HNF6 protein was found to respond only to $\mathrm{SMSeC}$ supplementation but not to sodium-selenate supplementation. Finally, fibrinogen showed a significant increase in abundance only when the diet was supplemented with sodium-selenate. In this way, the response of rats to dietary supplementation with different selenium compounds was partially characterized. Some proteins increased their abundance in the blood plasma depending on the chemical form of selenium that was included in the diet. Thus, the protein patterns observed in this work could probably be proposed as new molecular biology-based markers of selenium intake.

\section{ACKNOWLEDGEMENTS}

This work was partially supported by Grant 1061154 from Fondo Nacional de Desarrollo Científico y Tecnológico (FONDECYT - Chile) and Departamento de Gestión Tecnológica from Universidad de Santiago de Chile. The authors thank Dr. 
Remigio López for valuable assistance in the writing of this article.

\section{REFERENCES}

BHATTACHARYYA RS, HUSBECK B, FELDMAN D, KNOX SJ (2008). Selenite Treatment Inhibits LAPC-4 Tumor Growth and Prostate-Specific Antigen Secretion in a Xenograft Model of Human Prostate Cancer. Int J Radiat Oncol Biol Phys (doi: 10.1158/15357163.MCT-07-2142)

CLARK J, COMBS G, TURNBULL B, SLATE E, CHALKER D, CHOW J, DAVIS L, GLOVER R, GRAHAM G, GROSS E, KRONGARD A, LESHER J, PARK H, SANDERS B, SMITH C, TAYLOR J (1996). Effects of selenium supplementation for cancer prevention in patients with carcinoma of the skin. J Am Med Assoc 276: 1957-1963

CLARK LC, DALKIN B, KRONGRAD A, COMBS GF, TURNBULL BW, SLATE EH, WITHERINGTON R, HERLONG JH, JANOSKO E, CARPENTER D, BOROSSO C, FALK S, ROUNDER J (1998). Decreased incidence of prostate cancer with selenium supplementation: results of a double-blind cancer prevention trial. Br J Urol 81: 730-734

FINLEY JW, DAVIS CD, FENG Y (2000). Selenium from high selenium broccoli protects rats from colon cancer. J Nutr 130: 2384-2389

FINLEY JW, DAVIS CD (2001). Selenium from highselenium broccoli is utilized differently than selenite, selenate and selenomethionine, but is more effective in inhibiting colon carcinogenesis. BioFactors 14: 191196

FLEMING J, GHOSE A, HARRISON P (2001). Molecular mechanisms of cancer prevention by selenium compounds. Nutr Cancer 40: 42-49

GROMADZIDDSKA J, RESZKA E, BRUZELIUS K, WASOWICZ W, AKESSON B (2008). Selenium and cancer: biomarkers of selenium status and molecular action of selenium supplements. Eur J Nutr 47 Suppl 2: 29-50

GROVE H, HOLLUNG K, UHLEN AK, MARTENS H, FAERGESTAD EM (2006). Challenges related to analysis of protein spot volumes from two-dimensional gel electrophoresis as revealed by replicate gels. J Proteome Res 5: 3399-3410

GUNDIMEDA U, SCHIFFMAN JE, CHHABRA D, WONG J, WU A, GOPALAKRISHNA R (2008). Locally generated methylseleninic acid induces specific inactivation of protein kinase $\mathrm{C}$ isoenzymes: Relevance to selenium-induced apoptosis in prostate cancer cells. J Biol Chem (doi: 10.1074/ jbc.M807007200)

GUPTA N, SHANKERNARAYAN P, DHARMALINGAM K (2007). Serum proteome of leprosy patients undergoing erythema nodosum leprosum reaction: regulation of expression of the isoforms of haptoglobin. J Proteome Res 6: 3669-3679

HELLMAN U, WERNSTEDT C, GOÑEZ J, HELDIN CH (1995). Improvement of an "In-Gel" digestion procedure for the micropreparation of internal protein fragments for amino acid sequencing. Anal Biochem 224: 451-455

HURWITZ BE, KLAUS JR, LLABRE MM, GONZALEZ A, LAWRENCE PJ, MAHER KJ, GREESON JM, BAUM MK, SHOR-POSNER G, SKYLER JS, SCHNEIDERMAN N (2007). Suppression of human immunodeficiency virus type 1 viral load with selenium supplementation: a randomized controlled trial. Arch Intern Med 167: 148-154

IP C, BIRRINGER M, BLOCK E, KOTREBAI M, TYSON J, UDEN P, LISK D (2000). Chemical speciation influences comparative activity of selenium-enriched garlic and yeast in mammary cancer prevention. J Agr Food Chem 48: 2062-2070

IRONS R, CARLSON B, HATFIELD D, DAVIS C (2006). Both selenoproteins and low molecular weight selenocompounds reduce colon cancer risk in mice with genetically impaired selenoprotein expression. J Nutr 136: 1311-1317

JACOBSON B AND LOCKITCH G (1988). Direct determination of selenium in serum by graphite-furnace atomic absorption spectrometry with deuterium background correction and reduced palladium modifier: age-specific reference ranges. Clin Chem 34: 709-714

JOHTATSU T, ANDOH A, KURIHARA M, IWAKAWA H, TSUJIKAWA T, KASHIWAGI A, FUJIYAMA Y, SASAKI M (2007). Serum concentrations of trace elements in patients with Crohn's disease receiving enteral nutrition. J Clin Biochem Nutr 41: 197-201

KIM SW, HWANG HJ, CHO EJ, OH JY, BAEK YM, CHOI JW, YUN JW (2006). Time-dependent plasma protein changes in streptozotocin-induced diabetic rats before and after fungal polysaccharide treatments. J Proteome Res 5: 2966-2976

KOHRLE J (1992). The trace components -selenium and flavonoids- affect iodothyronine deiodinases, thyroid hormone transport and TSH regulation. Acta Med Austriaca 19: 13-17

LI L, XIE Y, EL-SAYED WM, SZAKACZ JG, FRANKLIN MR, ROBERTS JC (2006). Chemopreventive activity of selenocysteine prodrugs against tobacco-derived nitrosamine (NNK)-induced lung tumors in the $\mathrm{A} / \mathrm{J}$ mouse. J Biochem Mol Toxicol 19: $396-401$

LI S, YUN J, XUE F, BAI C, YANG S, QUE H, ZHAO X, WU Z, WANG Y, LIU S (2007). Comparative proteome analysis of serum from acute pulmonary embolism rat model for biomarker discovery. J Proteome Res 6: 150-159

LI Z, CARRIER L, ROWAN BG (2008). Methylseleninic acid synergizes with tamoxifen to induce caspasemediated apoptosis in breast cancer cells. Mol Cancer Ther 7: 3056-3063

MAZUR A, NASSIR F, GUEUX E, MOUNDRAS C, BELLANGER J, GROLIER P, ROCK E, RAYSSIQUIER Y (1996). Diets deficient in selenium and Vitamin E affect plasma lipoprotein and apolipoprotein concentrations in the rat. Br J Nutr 76: 899-907

MEDINA D, THOMPSON HT, GANTHER H, IP C (2001). Se-methylselenocysteine: A new compound for chemoprevention of breast cancer. Nutr Cancer 40: 1217

NAVAB M, MALLIA A, KANDA Y, GOODMAN D (1977). Rat plasma prealbumin. Isolation and partial characterization. J Biol Chem 252: 5100-5106

O'FARRELL P H (1975). High resolution two-dimensional electrophoresis of proteins. J Biol Chem 250: 40074021

PAGMANTIDIS V, MÉPLAN C, VAN SCHOTHORST EM, KEIJER J, HESKETH JE (2008). Supplementation of healthy volunteers with nutritionally relevant amounts of selenium increases the expression of lymphocyte protein biosynthesis genes. Am J Clin Nutr 87: 181-189

ROSENFELD J, CAPDEVIELLE J, GUILLEMOT JC, 
FERRARA P (1992). In-gel digestion of proteins for internal sequence analysis after one- or twodimensional electrophoresis. Anal Biochem 203: 173179

RUZ M, J CODOCEO, GALGANI J, MUÑOZ L, GRAS N, MUZZO S, LEIVA L, BOSCO C (1999). Single and multiple selenium - zinc - iodine deficiencies affect rat thyroid metabolism and ultrastructure. J Nutr 129: 174180

SAFARINEJAD MR, SAFARINEJAD S (2009). Efficacy of selenium and/or $\mathrm{N}$-acetyl-cysteine for improving semen parameters in infertile men: a double-blind, placebo controlled, randomized study. J Urol 18: 741751

SCHMUTZLER C, MENTRUP B, SCHOMBURG L, HOANG-VU C, HERZOG V, KOHRLE J (2007). Selenoproteins of the thyroid gland: expression, localization and possible function of glutathione peroxidase 3. Biol Chem 388: 1053-1059

SENGUPTA A, CARLSON BA, HOFFMANN VJ, GLADYSHEV VN, HATFIELD DL (2008). Loss of housekeeping selenoprotein expression in mouse liver modulates lipoprotein metabolism. Biochem Biophys Res Commun 365: 446-452

SHALINI S AND BANSAL MP (2007). Co-operative effect of glutathione depletion and selenium induced oxidative stress on AP1 and NFkB expression in testicular cells in vitro: insights to regulation of spermatogenesis. Biol Res 40: 307-317

SUNDE RA, PATERSON E, EVENSON JK, BARNES KM, LOVEGROVE JA, GORDON MH (2008). Longitudinal selenium status in healthy British adults: assessment using biochemical and molecular biomarkers. Br J Nutr 99 Suppl 3: S37-47

SUZUKI, KT (2005). Metabolomics of selenium: Se metabolites based on speciation studies. J Health Sci 51: $107-114$

TOLEDO H, VALENZUELA M, RIVAS A, JEREZ C (2002). Acid stress response in Helicobacter pylori. FEMS Microbiol lett 213: 67-72

UNNI E, KOUL D, YOUNG WK, SINHA R (2005). Semethylselenocysteine inhibits phosphatidylinositol 3kinase activity of mouse mammary epithelial tumour cells in vitro. Breast Cancer Res 7: R699-R707

YANG F, BRUNE JL, BALDWIN WD, BARNETT DR, BOWMAN BH (1983). Identification and characterization of human haptoglobin cDNA. Proc Natl Acad Sci U.S.A. 80: 5875-5879

ZHUO H, SMITH AH, STEINMAUS C (2004). Selenium and lung cancer: a quantitative analysis of heterogeneity in the current epidemiological literature. Cancer Epidemiol Biomarkers Prev 13: 771-778 
